\title{
The MIND Annual Conference, 1981
}

\author{
Greg Wilkinson, Joint Senior Registrar, King's College and Maudsley Hospitals
}

MIND is the leading mental health pressure group in England and $W$ ales and it has the following, uncontentious main goals: firstly, to improve and develop services for the mentally disordered; and secondly, to promote discussion in the community of issues which are relevant to mental health. Aims which most of us in psychiatry would support, surely? However, in recent years an unhealthy mutual distrust has arisen between this organization and many psychiatrists. Certainly the blame for the present unfriendliness is due, mainly, to MIND's legal and welfare rights department: their active, confrontational, campaigning style sometimes seems inappropriate, and often results in hostility (Roth, 1980). It is welcome, therefore, to note hints of a rapprochement (Smythe, 1981). Indeed, further evidence of an amelioration in the relationship was detectable at the MIND Annual Conference, which was held in London on 26 and 27 October 1981 and was entitled 'Psychiatric Treatment-Art or Science?' Even so, only $2 \%$ of the 600 delegates were clinical psychiatrists.

In contradistinction, academic psychiatrists were to the fore among the speakers at the plenary sessions. Professor SydNEY BRANDON (Leicester University) and DR HEINZ WoLfF (University College Hospital) both agreed that rational psychiatric treatment is based upon a mixture of intuition and systematic knowledge, and they stressed that there was still a need for mental health professionals to take a more critical attitude toward their treatment interventions. Dr Julian LefF (MRC Social Psychiatry Unit) then proceeded to give an excellent exposition of the art of working with the families of schizophrenic patients. The work he described is an extension of his previous research into the relationship between 'expressed emotion' and relapse in schizophrenics, and is to be published soon. From the point of view of the Conference, he was able to show clearly that a complicated social and psychological treatment was nevertheless open to scientific evaluation. Preliminary results indicate that a form of group therapy with the family can help reduce the tendency to relapse in high-risk patients. Furthermore, these therapeutic endeavours, unlike some treatments, are cheap enough to be made available on a general scale.

Dr Victor Meyer (Reader in Clinical Psychology, Middlesex Hospital) gave his usual persuasive and pungent account of the merits of 'analytic behaviourism'. His evident enthusiasm for this psychological treatment suggested the question 'What makes a competent psychotherapist?' Fortunately, DR Fraser W ATTS (formerly Head of Clinical Psychology, King's College Hospital) addressed himself to this problem. A thorough review of the literature failed to bring forward confirmation that any one psychological treat- ment had an overwhelming superiority over the others, but rather that different patients could respond to a variety of treatments. The best therapists were experienced and eclectic and used 'expedient virtuosity' as well as accurate empathy. Experience of a particular personal therapy or the acquisition of academic qualifications did not, apparently, make better therapists. (As far as Dr Wolff was concerned, most of this seemed to be very debatable.) On the other hand, therapeutic incompetence was easy to recognize, for such therapists were cold or hostile emotionally, trying to meet their own 'needs' in therapy and setting inappropriate goals without flexibility or sensitivity of approach. None of these descriptions could be directed at Dr Robert Palmer (Senior Lecturer, Leicester University) who, as the self-styled 'token biological' psychiatrist at the Conference, gave a fine account of the standing of physical treatment in contemporary psychiatric practice.

The sub-plenary sessions were more wide-ranging in content. Three concerned the future training of psychiatrists, nurse therapists, and specialist mental health social workers. Unfortunately, there was no consideration of the difficulties these professionals sometimes experience in having to work together. DR LIPSEDGE (Guy's Hospital) presented a session on psychosis and Caribbean immigrants. MiCHAEL ARGYLE (Reader in Social Psychology, Oxford University) and Geoff ShePherd (Principal Psychologist, Fulbourn Hospital) had different opinions on the value of social skills treatment. Lastly, DR ALEX Theodossaidis (North Manchester General Hospital) and two of his patients exchanged views about psychiatric treatment. This proved to be a worthwhile exercise since both consumers had forceful constructive criticisms to make. Patient perspectives on psychiatric treatment was one of the background themes over the two days, and one unresolved conflict for some mental health workers emerged here-how far, and in what circumstances, can informed patients/clients be allowed to take a direct and full partnership in the decision-making process regarding their treatment?

Dr ANTHONY Clare (Senior Lecturer, Institute of Psychiatry), MIND's medical adviser, brought the well-run Conference to a close with a typically witty but nonetheless penetrating account of the likely future for psychiatric treatment (and also for psychiatry!). In keeping with current economic trends, the mental health industry needed to become competitive if it wanted to increase its share of the market and expand. Expertise and funds for psychiatric services and research would be forthcoming, it was suggested, if psychiatrists and their professional colleagues now scrutinized their efforts, made sure of the efficiency and effectiveness of their treatment measures, and began to point 
to their achievements, confidently, as did those in other medical specialties. Otherwise, the present services might deteriorate for the most disadvantaged groups, as well as for the majority of people with minor psychiatric morbidity who are seen in general practice. These observations were, ironically, pertinent to MIND, since the organization itself is in financial trouble. Without doubt, a reduction in MIND's enterprise would be disadvantageous and a disappointment to the mental health movement.

\section{REFERENCES}

RoTH, M. (1980) MIND and its policies. The Times, 13 September. SMYTHE. T. (1981) The role of MIND in relation to psychiatry. Bulletin of the Roval College of Psychiatrists, 5, 140-43.

\section{Forthcoming Events}

The Section of Psychiatry of the Royal Society of Medicine is continuing its season of talks and discussions with the following themes: 9 February 1982-'Is the term psychosomatic disease of any value?', Professor Sir Desmond Pond; 9 March 1982 - The role of dynamic psychotherapy in the National Health Service', Dr Malcolm Pines, Dr I. S. Kreeger and Dr C. J. Allison; 6 April 1982six papers on 'Ongoing research', speakers to be announced. Information: Section of Psychiatry of the Royal Society of Medicine, 1 Wimpole Street, London W1M 8AE.

An all-day symposium on 'Drug Dependence' will be held in the Kent Postgraduate Medical Centre, Kent and Canterbury Hospital on 13 February 1982. Information: Mrs M. M. Allen, Kent and Canterbury Hospital, Canterbury CT1 3NG.

The Association for Family Therapy, Mid Wales Group, is organizing a two-day residential conference on sticking points and difficulties in family therapy on 22 and 23 April 1982 at Gregynog, University of Wales, Newtown, Powys. Conference fee £45. Information: Margaret Turney, Medical Library, Mid Wales Hospital, Talgarth, Brecon, Powys (telephone: (0874) 711671, ext. 267).

Cruse (National Organization for the Widowed and their Children) is again arranging a course of ten group discussions and lectures on counselling before and after bereavement beginning on 20 January 1982 and ending on 24 March 1982. The course is to be held at Imperial College, London, and is open to doctors, social workers, ministers of religion, nurses, health visitors, educationalists and all who are professionally involved with dying and bereaved people. Information: Dr Dora Black, Cruse, Cruse House, 126 Sheen Road, Richmond, Surrey (telephone: 01940 4818/9047).
An International Conference for the Mental Health of the Elderly will be held in Cairo from 22 to 25 November 1982. Information: Dr A. M. Ashour, PO Box 290, Heliopolis, Egypt.

The Sixth Congress of the International Association for the Scientific Study of Mental Deficiency will be held in Toronto from 22 to 26 August 1982. Those interested in presenting papers or attending the congress should contact either Professor G. A. Roeher (Programme Chairman), National Institute of Mental Retardation, York University Campus, 4700 Keele Street, Downsview, Ontario, Canada M3J 1P3 or Dr D. A. Primrose (Programme Secretary), Physician Superintendent, The Royal Scottish National Hospital, Larbert, Stirlingshire, Scotland.

The 9th World Congress of Social Psychiatry will be held in Paris from 5 to $9 \mathrm{July,}$ 1982. This Congress is organized by the Association Française de Psychiatrie Sociale. Information: PMV-Congrès, 100 Avenue Charles de Gaulle, 92522 Neuilly Cedex, France.

'The Treatment of Depression' is the theme of a seminar to be held at The Priory Hospital on 28 January 1982, with $\mathrm{Dr}$ John Horder, President of the Royal College of General Practitioners, in the Chair. Topics include 'New Antidepressant Drugs', 'The Management of Side-Effects', 'Lithium Prophylaxis' and 'Cure, Control or Prevention'. Discussion opened by Sir Desmond Pond. Information: $\mathrm{Dr}$ Desmond Kelly. The Priory Hospital, Priory Lane, London SW15 5JJ.

The next course of 'Current Themes in Psychiatry' is to be held at Leeds Castle in Kent from 20 to 26 March 1982. The course is open to consultant and senior psychiatrists. Accommodation can be arranged if necessary. Information: Mrs Carlisle, New Cross Hospital, Avonley Road, London SE14 5ER (telephone: 01-639-4380, ext. 4339). 